\title{
The Effect of Iron Oxide Nanoparticles on Sperm Numbers and Mobility in Male Mice
}

\author{
Sima Nasri, ${ }^{1, *}$ Saeid Rezai-Zarchi, ${ }^{1}$ Parisa Kerishchi, ${ }^{2}$ and Safora Sadeghi ${ }^{1}$ \\ ${ }^{1}$ Department of Biology, Payame Noor University, Tehran, IR Iran \\ ${ }^{2}$ Department of Biology, Shahr-e-Qods Branch, Islamic Azad University, Tehran, IR Iran \\ *Corresponding author: Sima Nasri, Department of Biology, Payame Noor University, Tehran, IR Iran. E-mail: s_nasri1@pnu.ac.ir
}

Received 2012 August 2; Accepted 2012 August 30.

\begin{abstract}
Background: Now a day, $\mathrm{Fe}_{2} \mathrm{O}_{3}$ nanoparticles due to high magnetic property and small size are used in MRI imaging. Objectives: This study aimed to characterize the effect of iron oxide nanoparticles on sperm parameters.

Materials and Methods: This experiment study was carried out on 75 mature male mice that divided into 4 test groups that received iron oxide nanoparticles at the dose levels of 5,10,20, $40 \mathrm{mg} / \mathrm{kg}$ intraperitaneally (i.p.) for 2 weeks and a control group. Sperm was collected from epididymis and prepared for analysis.

Results: $\mathrm{Fe}_{2} \mathrm{O}_{3}$ nanoparticles cause a meaningful reduction in sperm numbers and mobility in all experimental groups.

Conclusions: Nanoparticles can cause the inflammation of epididymis and increasing of free radicals (Reactive oxygen species: ROS) that can decrease the mobility of the sperms.
\end{abstract}

Keywords: Nanoparticles, Sperm, Male, Mice

\section{Background}

Now a day, nanoparticles is used in most industries because of their properties. The important features of iron oxide nanoparticles such as fast effect, high magnetic property and small size are caused that iron oxide nanoparticles will be used as a contrast agent in MRI (Magnetic Resonance Imaging) and NMRI (Nuclear Magnetic Resonance Imaging) and the diagnosis of cancers.

It has reported that some nanoparticles make reactive oxygen (Reactive oxygen species: ROS) [1] and cause toxicity in lab environment [1]. Very small size, large surface area and reactiveness of nanoparticles will expose people to serious dangers potentially. Nanoparticles can easily cross the cell membrane [2] and block blood-testicular [3]. The toxicity of iron oxide nanoparticles by creating changes in $\mathrm{pH}$ and serum concentration has been reported [4]. The studies which were performed on mice about $\mathrm{Tio}_{2}$ nanoparticles showed that nanoparticles can be seen in Leydig cells, Sertoli and spermatids [5]. In another report the effect of black carbon nanoparticles on the performance of male genital system were investigated, decreased daily sperm production. Testicular morphology changes especially Leydig cells and the reduction of testosterone density [6]. The effects of nanoparticles in various cells have decreased mitochondrial activity [7]. However, in spite of the importance of reproductive system a few studies have done on the iron oxide nanoparticles effects on sexual cells.

\section{Objectives}

The present investigation was set to evaluate the effect of iron oxide nanoparticles on male sexual cells and sexual hormones.

\section{Materials and Methods}

In this experiment study, iron oxide nanoparticles with a diameter of $30 \mathrm{~nm}$ were purchased from the Nano Technology Research Center of Yazd Payame Noor University. First, $300 \mathrm{~mL}(0.2 \mathrm{M})$ of iron nitrate $\mathrm{Fe}\left(\mathrm{NO}_{3}\right)_{3} \cdot 9 \mathrm{H}_{2} \mathrm{O}$ (Aldrich 98\%) was used as a precursor solution, and was gelated by using $800 \mathrm{~mL}$ of mono hydrated citric acid (Aldrich 98\%) solution (0.05 to 0.3 $\mathrm{M}$ ) as ligands with a molar ratio of 1:1 were distilled water as the solvent. The iron solution was added to the citric acid solution drop wise with vigorous stirring. The solution was then heated to a temperature of $80^{\circ} \mathrm{C}$, while maintaining vigorous stirring until the gel was formed and the contained water was evaporated. The 
Nasri S et al.

dried gel was annealed at temperatures ranging from $200-400^{\circ} \mathrm{C}$, typically yielding $\mathrm{Fe}_{2} \mathrm{O}_{3}$ ranging in size from $20-30 \mathrm{~nm}$. Then, they were deyonized and were changed to a solution and were prepared in different concentration $5,10,20,40 \mathrm{mg} / \mathrm{kg}$. There is not any coating to review the features of this nanoparticle dispersion was performed crystal X-ray diffractometer (XRD) for the confirmed the crystal structure and for the average size of the particles. However for nanoparticle size composite photo electron microscope (Transmission electron microscopy: TEM) was used to set both of these analysis showed that the synthesis of nanoparticles in diameter of about $20 \pm 5 \mathrm{~nm}$ found with using the Scherrer formula [1].

In this study, 57 mice (were purchased from Pastor Institute, Tehran, Iran) were used. Mice randomly divided into 5 groups $(\mathrm{N}=15)$ : control group and 4 experimental groups that received iron oxide nanoparticles at the dose levels of 5, 10, 20, $40 \mathrm{mg} / \mathrm{kg}$ intraperitaneally (i.p.) for 2 weeks [8]. This research was approved with ethics committee of Payame Noor University. The mice were kept under standard conditions $[8,9]$.

One week after the last injection (after passing the spermatogenesis period) the mice were anesthetized by chloroform, then the abdomen of animals was opened and reproductive organs (testis and epididymis) were removed.

Epididymises were dissected out, immediately minced in $5 \mathrm{~mL}$ of physiological saline and then incubated at $37^{\circ} \mathrm{C}$ for 30 minutes to allow sperms to leave the epydidimal tubules $[8,9]$. The cauda epididymis sperm were determined using the standard hemocytometris method.

For the histological examination, small pieces of testis were fixed in $10 \%$ formalin, dehydrated and then sectioned. Sections were then stained with Hematoxylin and Eosin and examined under light microscope [8].

Statistical analysis was performed with SPSS-13. All parameters were analyzed by one way ANOVA and the obtained data were expressed as Mean \pm SD. For parameters with significant differences among groups, multiple comparison tests were carried out $(\mathrm{P}<0.05)[8,9]$.

\section{Results}

TEM and XRD analysis showed that the synthesis of nanoparticles has a diameter of about $20 \pm 5 \mathrm{~nm}$.

The number of sperms was significantly reduced in all experimental groups $(\mathrm{P}<0.001)$. Percentage of mobile sperms, decreased in all experimental groups significantly $(\mathrm{P}<0.001)$ (Figures 1 and 2 ).

Investigation of seminiferous tubules showed reduction of Spermatocytes and spermatids detachment of Spermatogonia and Spermatocytes from the wall of the tubule and the release of sperm precursor cells into the middle of the tubule.
Figure 1. Effect of Iron Oxide Nanoparticles on Sperm Mobility in All Experimental Groups

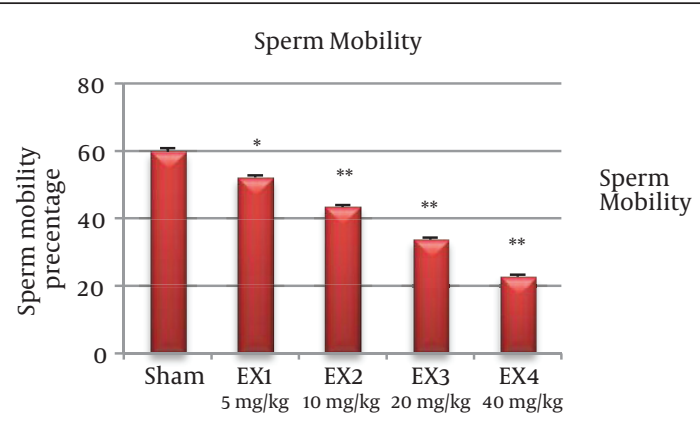

Percentage of mobile sperm reduced relation to control group significantly; *, ${ }^{*}$ Difference with control group $(\mathrm{P}<0.05)$ and $(\mathrm{P}<0.001)$.

Figure 2. Effect of Iron Oxide Nanoparticles on Sperm Numbers in All Experimental Groups

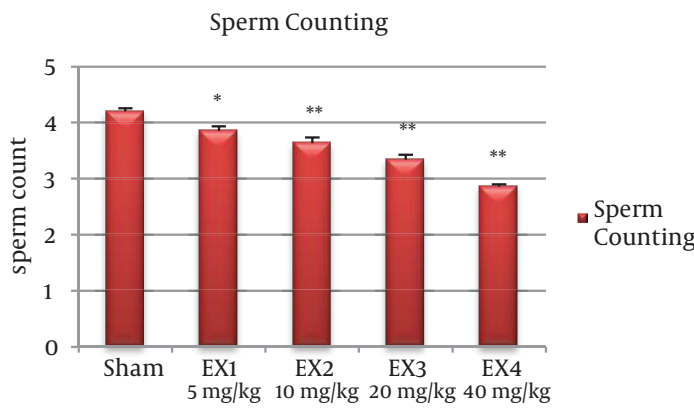

*, ** Indicate significant difference with control group $(\mathrm{P}<0.05)$ and $(\mathrm{P}$ $<0.001)$.

\section{Discussion}

The investigation of sperm mobility in the epydidimal area shows that the percentage of sperm mobility in the mice in experimental group in relation to control group has had a meaningful decrease, that it can be said the reason is related to the effect of iron oxide nanoparticles on mitochondrial action [5].

The researches which have done on the effect of nanoparticles on mitochondrial action in different cells have shown the reduction of mitochondrial action in all cases [5]. The studies which performed by Braydich-Stolle et al. on the line 4 - 18 cells showed that nanoparticles such as iron oxide and silver can cross the membrane of sperm and they can connect to mitochondria and acrosome of sperm [5]. On the other hand, sperm mobility was happened in epididymis the investigation shows that nanoparticles can effect on epididymis and cause the inflammation of epididymis that it can reduce sperm mobility. Also nanoparticles in cells cause the increasing of ROS that this can decrease the mobility of the cells by damaging to the flagella structure of the sperms [10]. 
Nasri S et al.

Metal nanoparticles increase ROS such as super oxide which may cause the inhibit of RNA polymerase [10], the oxidation of molecules such as protein and even DNA and in this way they cause the decrease of LH, testosterone and Leydig cells [11].

Histopathological examination and statistical analysis shows that the number of sperms in all experimental groups has been decrease. Iron oxide nanoparticles can damage the DNA of leyding cells; the apoptosis of these cells and at last cause their death [12].

This study was showed iron oxide nanoparticles have negative effects on sperms and it is suggested that the effect of iron oxide nanoparticles on Leydig cells occurs at the molecular level.

\section{Acknowledgments}

All people who have assisted us to conduct this study, particularly Mr. Imani are cordially appreciated. This article has been taken from the thesis of Safora Sadeghi MSc student with code of 4884 .

\section{Footnote}

Funding/Support:This study was conducted with financial support of Payame Noor University.

\section{References}

1. Mahmoudi M, Simchi A, Imani M, Shokrgozar MA, Milani AS, Hafeli UO, et al. A new approach for the in vitro identification of the cytotoxicity of superparamagnetic iron oxide nanoparticles. Colloids Surf B Biointerfaces. 2010;75(1):300-9. doi: 10.1016/j.colsurfb.2009.08.044. [PubMed:19781921]

2. Gopinath P, Gogoi SK, Chattopadhyay A, Ghosh SS. Implications of silver nanoparticle induced cell apoptosis for in vitro gene therapy. Nanotechnology. 2008;19(7):075104. doi: 10.1088/09574484/19/7/075104. [PubMed: 21817629]

3. Lan Z, Yang WX. Nanoparticles and spermatogenesis: how do nanoparticles affect spermatogenesis and penetrate the bloodtestis barrier. Nanomedicine (Lond). 2012;7(4):579-96. doi:10.2217| nnm.12.20. [PubMed: 22471721]

4. Nel A, Xia T, Madler L, Li N. Toxic potential of materials at the nanolevel. Science. 2006;311(5761):622-7. doi: 10.1126/science.1114397. [PubMed:16456071]

5. Braydich-Stolle L, Hussain S, Schlager JJ, Hofmann MC. In vitro cytotoxicity of nanoparticles in mammalian germline stem cells. Toxicol Sci. 2005;88(2):412-9. doi: 10.1093/toxsci/kfi256. [PubMed: 16014736]

6. Yoshida S, Hiyoshi K, Ichinose T, Takano H, Oshio S, Sugawara I, et al. Effect of nanoparticles on the male reproductive system of mice. Int J Androl. 2009;32(4):337-42. doi: 10.1111/j.13652605.2007.00865.x. [PubMed: 18217983]

7. Bentley GE, Ubuka T, McGuire NL, Chowdhury VS, Morita Y, Yano T, et al. Gonadotropin-inhibitory hormone and its receptor in the avian reproductive system. Gen Comp Endocrinol.2008;156(1):3443. doi:10.1016/j.ygcen.2007.10.003. [PubMed: 18031743]

8. Jalali M, Saki G, Sarkaki AR, Karami K, Nasri S. Effect of noise stress on count, progressive and non-progressive sperm motility, body and genital organ weights of adult male rats. J Hum Reprod Sci. 2012;5(1):48-51. doi:10.4103/0974-1208.97801. [PubMed: 22870015]

9. Tabibian M, Nasri S, Kerishchi P, Amin G. The effect of gundelia tournefortii hydro-alcoholic extract on sperm motility and testosterone serum concentration in mice. Zahedan J Res Med Sci. 2013;15(8):18-21.

10. Yoshida Y, Itoh N, Saito Y, Hayakawa M, Niki E. Application of water-soluble radical initiator, 2,2'-azobis[2-(2-imidazolin-2-yl)propane] dihydrochloride, to a study of oxidative stress. Free Radic Res. 2004;38(4):375-84. [PubMed:15190934]

11. Stocco DM. The role of the StAR protein in steroidogenesis: challenges for the future. J Endocrinol. 2000;164(3):247-53. [PubMed: 10694364]

12. Komatsu T, Tabata M, Kubo-Irie M, Shimizu T, Suzuki K, Nihe $\mathrm{Y}$, et al. The effects of nanoparticles on mouse testis Leydig cells in vitro. Toxicol In Vitro. 2008;22(8):1825-31. doi: 10.1016/j. tiv.2008.08.009. [PubMed: 18805477] 